\title{
Web-based lecture technologies and learning and teaching: a study of change in four Australian universities
}

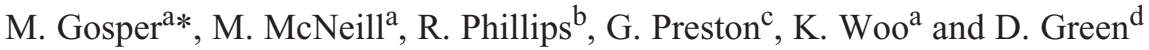 \\ ${ }^{a}$ Learning and Teaching Centre, Macquarie University, Sydney, Australia; ${ }^{b}$ Teaching and \\ Learning Centre, Murdoch University, Perth, Australia; ${ }^{C}$ School of Education, University of \\ Newcastle, Newcastle, Australia; ${ }^{d}$ Staff Development \& Training Unit, Flinders University, \\ Adelaide, Australia
}

(Received 11 February 2010; final version received 30 September 2010)

\begin{abstract}
The uptake of web-based lecture technologies for recording and delivering live lectures has increased markedly in recent years. Students have responded positively, and for many their use has transformed learning - freeing them up from rigid timetables by providing choice in lecture attendance and supporting learning by extending the lecture experience and enabling them to revisit key concepts and ideas in their own time. Less transformational has been the impact on teaching. Although changing attendance patterns and disquiet about the quality of learning are of concern to many, lecturers have largely responded by simply modifying lectures. For most, the challenges of catering for the learning needs of a cohort with variable lecture attendance have not been addressed at a whole of the curriculum level. The technologies have been added on, rather than integrated into the curriculum. This paper will review the changes taking place in learning and teaching, explore the reluctance to embrace more wholesale change to the curriculum, and discuss the implications for institutions in the face of ongoing change.
\end{abstract}

Keywords: web-based lecture technologies; Lectopia; learning technologies; higher education; lectures; change

\section{Introduction}

Educational innovation and change is multidimensional, involving individuals and organisations (Fullan 2001; Scott 1999). It is best achieved when it is accompanied by new teaching approaches and the alteration of beliefs (Fullan 2001), as well as taking into account disciplinary differences in teaching and learning, the educational research literature, and evidence about the benefits of the innovation (Nicol and Draper 2009). This paper reflects on these observations in relation to a cross-institutional study of the impact of web-based lecture technologies (WBLT) on learning and teaching at four Australian universities.

Web-based lecture technologies can be described as technologies that enable the automated recording of audio and visual elements of face-to-face lectures for processing in a variety of streaming media formats for web-based delivery. Students can

*Corresponding author. Email: maree.gosper@mq.edu.au 
access the recordings 24 hours a day, seven days a week. Lectopia (previously known as iLecture and also known as Echo 360) is one of these technologies.

Two of the four universities involved in the study initially implemented WBLT to replace outdated technology used to deliver lecture content to external students; however, both have extended its use to internal students to support flexible approaches to learning. In the third university the primary driver was as support for blended learning, and in the fourth it was largely in response to student demand.

The key findings about the nature of the changes taking place for students and their learning, teachers and their teaching and to the design of the curriculum will be reviewed. This will be followed by a discussion of the issues for consideration by universities as they endeavour to meet the challenges arising from an ever-changing, technology-rich environment.

\section{Background to the study}

The popularity of WBLT is growing, as can be seen in the increasing use of Lectopia in universities; for example, in Australia usage has gone from 10 of the 39 universities in 2007 to 16 in 2009. This, in part, can be explained by the reality of student life, which is one of balancing work and study. Again, using Australian statistics as an example, Anderson (2006) reported that 78\% of Australian students found that work impacted their study, which is backed up by a study by the Australian ViceChancellors Committee finding that $71 \%$ of Australian university students undertake paid employment during semester, working an average of 15 hours per week (Australian Vice-Chancellors Committee 2007).

The introduction of blended delivery models combining face-to-face lectures and tutorials with online resources, communication and collaboration opportunities (Lefoe and Hedberg 2006; Phillips 2005; Sharpe et al. 2006) is one response to the provision of the flexibility being sought by students. WBLT, with their ability to support a variety of delivery imperatives, are one of a number of technologies that can be called upon when designing flexible and blended programmes (Carter, Hodgson, and Sher 2005; Hodgson 2005).

Early studies emerging on the use of Lectopia found that, on the whole, students were positive about their experiences and were quick to make use of the technologies when they were unable to attend lectures for a variety of reasons, including timetabling clashes, illness, work and family commitments (Fardon 2003; McElroy and Blount 2006; Soong et al. 2006; Williams and Fardon 2007). In contrast, the responses from academic staff were mixed, with reported concerns arising from reduced attendance at lectures, loss of contact with students and disruptions to the continuity of the learning experience, particularly when tutorials were dependent on lecture attendance (Buxton et al. 2006; Massingham and Herrington 2006). In addition, there were concerns that these technologies, which are designed to replicate the traditional lecture, were reinforcing lecturing as a transmission model of teaching and discouraging more desirable interactive learner-centred experiences (Donnan, Kiley, and McCormack 2004).

Evaluations of the early use of WBLT at the four universities participating in the study mirrored these findings. The perceived and reported changes in students' lecture attendance patterns were thought to have impacted on the learning environment; however, the nature of the changes taking place to learning and teaching was not clear. A number of questions remained unanswered, such as: 
- How are students using the technologies to support their learning?

- What uses are teachers making of this technology as a learning (rather than delivery) tool?

- Are lecturers changing/having to change their teaching style to produce webbased lectures?

- How can the use of this technology contribute to good practice in learning and teaching?

- How can the curriculum be designed to make effective use of this type of technology?

The need for further investigation into the implication of these technologies for learning and teaching was evident; not only because of the proliferation and substantial cost investment by institutions in this area, but also because of the potential to make substantial improvements to teaching practice, to improve the student learning experience and to contribute to the development of effective mechanisms for the identification, dissemination and embedding of good individual and institutional practice in higher education.

\section{The project - the impact of WBLT on learning and teaching}

The research, funded by the Australian Learning and Teaching Council, was conducted as a cross-institutional study from 2006 to 2008. The aim was to provide a more comprehensive understanding of:

- how WBLT can effectively support learning and teaching;

- how WBLT are integrated into the curriculum; and

- the educational implications of their use.

A two-staged research design employing a mixed-methods approach (Creswell 2003) was used. The first stage involved surveys of students and staff to capture the diversity of experiences in the use of WBLT and to identify issues and usage patterns. Both quantitative and qualitative questions were used. The student survey included questions covering general demographics (age, gender, discipline, enrolment mode), effectiveness of WBLT, lecture attendance (frequency and rationale), experience of WBLT (use and rationale), and approaches to learning.

Students from courses making use of web-based lecture technologies at all four universities were invited to participate. Stratified sampling was used to obtain a mixture of discipline areas, class sizes, enrolment mode (internal and external students), and levels (undergraduate and postgraduate).

Invitations were sent to 13,278 students, but only those students who used WBLT were eligible to answer the survey. In total 815 responded, representing a subset of users. The actual response rate could not be determined because we were unable to identify the actual number of students using WBLT. Nonetheless, the sample size was large enough for valid conclusions to be drawn.

Of the respondents, $70.7 \%$ were female, $87.1 \%$ were enrolled as internal students and $13.9 \%$ as external, $91.1 \%$ were studying at undergraduate and $8.9 \%$ were at postgraduate level, $80.8 \%$ were full-time and $19.2 \%$ were part-time, more than half $(56.8 \%)$ were 24 years of age or younger, and 15\% reported that English was not their first language. 
The staff survey was designed to correspond with the student survey, so that results could be compared. In addition, information was collected on the teaching and curriculum context, the reasons for using WBLT, the teaching strategies adopted, perceptions of the effect of WBLT on lecture delivery, student attendance, and communication patterns between staff and their students. A total of 676 academic teaching staff were invited to participate in the survey, and $155(22.9 \%)$ responded from across the four universities.

The second stage of the study involved vignettes and case studies that aimed to provide a contextualised view of the issues that arose from the surveys. The vignettes were designed to be descriptive in nature to highlight the manifestations of particular issues and the resulting opportunities and challenges. An invitation to participate was included at the end of the student and staff surveys. Staff who were known to have used WBLT in innovative ways, or who had strong feelings about the impact of WBLT, were also sent the invitation. In total, six lecturers and 10 students were interviewed using a semi-structured instrument derived from the survey questions. In addition, questions were included to explore in more detail relevant points of interest that arose. Interviews were transcribed and then analysed to establish:

- student and staff perceptions about WBLT as positive or negative;

- how the tools are used by students and staff;

- main issues emerging for staff and students; and

- points of disconnect between staff and student perspectives.

Case studies of specific courses were selected to provide an in-depth analysis of the curriculum contexts and to provide multiple perspectives (from both staff and students). They involved small research projects that were both explorative and developmental in nature, which aimed to explore:

- the conditions under which lecture delivery technology use is desirable in different contexts;

- strategies for enhancing learning and teaching;

- implications for the design and delivery of the curriculum and the establishment of effective learning environments; and

- implications for academic policies and practice.

Staff were invited to submit an expression of interest, and six case studies were selected based on their innovative usage of WBLT or interesting curriculum contexts. Ethics approval was sought from the separate institutions at each stage of the project

\section{Results}

The key findings, drawn from the full project report (Gosper et al. 2008), are discussed below and cover the impact on students and their learning teachers and teaching, and the design of the curriculum.

Three of the four participating universities used different versions of Lectopia and the fourth made use of a combination of home-grown streaming video and audio applications. There were variations in the way the different media were used within and across universities, ranging from audio-only, to audio accompanied by PowerPoint slides, to full video. Delivery methods encompassed streaming, downloading to 
computers or mobile devices and podcasting. Despite this, the findings reported were consistent across all universities.

\section{Students and their learning}

The three main outcome measures used in the surveys were: positive experience with WBLT; perceptions of benefits for learning; and perceptions of achievement of better results. Regardless of age, gender, enrolment mode or attendance pattern, $76.3 \%$ of student respondents reported a positive experience always to frequently and only $11 \%$ rarely to never.

In response to perceptions of the technologies making it easier to learn, $79.9 \%$ of students agreed that it had, in either a significant or moderate way, $13.4 \%$ were not sure whether there was any change, and only $6.7 \%$ felt it did not help.

In response to whether students thought using WBLT helped them achieve better results, $66.7 \%$ of 813 agreed that it had, in either a significant or a moderate way, $23.3 \%$ were not sure whether there was any change, and $9.9 \%$ felt it did not help.

To explore how the technology influenced learning, students were asked to indicate their level of agreement, on a five-point Likert scale, with eight statements about the use of WBLT. The highest level of agreement was for picking up on things that were missed in class $(78.6 \%)$, followed by revising for examinations (76.4\%), reviewing complex ideas and concepts $(76.2 \%)$, working at your own pace (73.9\%), taking comprehensive notes $(62.5 \%)$, picking up on announcements and examination hints $(62.2 \%)$, revisiting material because the lecturer did not speak clearly $(20.8 \%)$, and revisiting material because English was not their first language (20.4\%).

Open-ended comments indicated strong endorsement of their value in widening access, supporting flexibility and facilitating learning:

Lecture Recordings are an invaluable tool for me ... I utilise them to facilitate learning $\&$ understanding. If it were not for lectures being recorded I would not have been able to study 2 of the subjects I did this semester due to family commitments.

I work full time and the subjects on iLecture mean that it does not disrupt my work day in fact I would have to give up my job and find a part time position. More subjects should be on iLecture.

It is an extremely good service and a great way to supplement one's learning by being able to follow up on concepts raised in the lecture and being able to listen to lecture's when one is sick and has not attended class.

I can validate a question before I ask it. I can listen to the lecture maybe a few times then really refine what I want to ask. I can then (with confidence) approach the lecturer to seek my answer based on accurate reflections not what I thought the lecturer said.

Distance students in particular valued WBLT, with reported benefits being:

- provision of up-to-date information;

- an increased sense of belonging; and

- provision of opportunities for interactions (reported more fully in Woo et al. 2008). 
Overall, our findings replicated those from other studies (Fardon 2003; McElroy and Blount 2006; Soong et al. 2006; Williams and Fardon, 2007), with students strongly endorsing WBLT for their ability to provide access to lectures, flexibility in attendance and support for learning.

\section{Teachers and teaching}

The two main reasons for lecturers providing WBLT were to support students who could not come to class ( $82 \%$ of respondents) and to provide another tool to help students learn $(65 \%)$. This was followed by supporting students with disabilities (49\%), supporting non-English-speaking students (47.1\%), responding to departmental requirements $(17 \%)$, responding to pressures from students $(11.6 \%)$, helping student cope with accents of lecturers (9.7\%), and avoiding repeating a lecture (3.2\%). Only 3.2\% used WBLT because they felt students could learn as well from the recording.

The difference in perceptions between staff and students of the effectiveness of WBLT for supporting learning and achieving better results is shown Table 1.

The clear endorsement of the technologies by students is contrasted by a mixed response from staff. Eighty per cent of students compared with $49 \%$ of staff perceived WBLT made it moderately to significantly easier to learn. Sixty-seven per cent of students compared with $29 \%$ of staff perceived WBLT helped to achieve better results.

The value to external students was not disputed but the perceived value for internal students was questioned.

It does support external students. ... On many points I would argue that [WBLT] enhance the study experience of external students, but generally diminish the study experience of internal students.

For internals I think it can help them to justify not coming to lectures. They think, "it's OK not to go, I'll listen to the iLecture later". I fear later never comes or comes too late and they cram for assessment. Externals, however, brilliant!

There was a belief by many staff that learning was dependent on lecture attendance. This belief was not held by students. While $68.3 \%$ of the students surveyed agreed that they could learn just as well from the technology as they could from the face-to-face lecture, only $3.2 \%$ of staff agreed with this statement.

Table 1. Comparison of student and staff perceptions of the effectiveness of WBLT.

\begin{tabular}{|c|c|c|c|c|}
\hline & \multicolumn{2}{|c|}{ WBLT makes it easier to learn (\%) } & \multicolumn{2}{|c|}{$\begin{array}{l}\text { WBLT has helped to achieve better } \\
\text { results }(\%)\end{array}$} \\
\hline & Students $(n=746)$ & $\operatorname{Staff}(n=139)$ & Students $(n=746)$ & Staff $(n=139)$ \\
\hline Yes - significantly & 47.1 & 12.2 & 35.1 & 7.9 \\
\hline Yes - moderately & 32.8 & 36.7 & 31.6 & 22.3 \\
\hline Not sure & 13.4 & 38.1 & 23.3 & 54.7 \\
\hline No - didn’t help & 5.6 & 7.2 & 8.6 & 9.4 \\
\hline No - detrimental & 1.1 & 5.8 & 1.3 & 5.8 \\
\hline
\end{tabular}


The mismatch between student and staff perceptions presents an interesting conundrum. On the one hand, lecturers are using the technology to support flexibility and to provide an additional learning tool, and on the other they do not believe it is an effective tool for learning.

Scott (1999) argues that no educational change ever unfolds as planned and there will always be that unexpected twist or surprise. With the introduction of WBLT, the fall in lecture attendance was an unexpected surprise for many lecturers. Just over onehalf $(55 \%)$ of the respondents felt that WBLT had resulted in decreased lecture attendance; however, $24 \%$ reported no difference. Student data verified perceptions of falling attendance, with 56\% reporting they attended lectures frequently, $13.3 \%$ half the time and $25.7 \%$ rarely.

It is not clear, however, whether WBLT were the sole cause of falling attendance. It is well recognised that student attendance decreases during the semester and increasing employment and lifestyle pressures make it harder for students to engage as deeply in the university experience as those from previous decades (Maag 2006; Massingham and Herrington 2006).

Further exploration of the importance of lecture attendance revealed concerns that students were not aware of what they do not know. There were also concerns that students not in attendance were missing the audio-visual and copyrighted material that is not available through the recordings, the incidental discussions that take place, and the networking and sense of community that can develop through personal contact. Some identified the lack of opportunity to receive feedback from students about how well they understood the lecture and unit content. In addition, there was the concern for students falling behind if they do not attend regularly, and related to this is the potential for discontinuity between lectures and follow-on tutorials.

Changes to the ephemeral nature of lectures were also of concern to some lecturers. Knowing that the lecture was available in downloadable format to students, staff and others had caused many to reflect on how their comments could be interpreted without the accompanying contextual cues, body language and expressions of a live performance. Falling attendance was also reported as reducing the dynamism of lectures. As noted by several staff, with small numbers in a large classroom, it is hard to be motivated and dynamic.

Lectures are often an uncontested part of the culture of university teaching (Phillips 2005). Pratt and Collins (2001) maintain that many academics have a teaching perspective with a focus on nurturing their students, and a key mechanism for this is through the personal contact during and after lectures. This may go some way towards explaining why they perceive falling attendance as problematic. Another, arising from research by Hanson (2009) on e-learning and academic identity could be a strong desire of academics to protect their face-to-face relationship with their students as this has become a powerful feature of academic identity.

Some action has been taken by lecturers in response to the changing nature of the lecture experience $-43.2 \%$ of staff indicated they have not changed their lecturing style, while $36.7 \%$ have done so. Various adaptations were reported, including the following:

- becoming more aware of spontaneous comments in lectures;

- adjusting activities/interactions to cater for students who are present as well as those using WBLT;

- reducing movement around the lecture theatre; 
- reducing multimedia content due to copyright restriction;

- listening to recordings and adjusted my performance; and

- scripting the lecture more tightly to provide a more controlled presentation.

While laudable, these strategies are primarily focused on modifying existing lecture content and the lecturing process. All the same, it is questionable whether they will adequately deal with the concerns arising from decreased communication, networking and feedback opportunities, as well as the discontinuity between lectures and other activities. These concerns extend beyond lectures to encompass the broader curriculum.

\section{Impact on the curriculum}

Some lecturers have taken the opportunity to reflect on the relationship of lectures within the whole curriculum and have made various adaptations. The changes encompassed integrating other activities by utilising online forums to gather feedback and to discuss issues and themes emerging from the lecture, using formative assessment approaches to promote engagement, and staging tasks to encourage students to keep a steady pace of study.

These lecturers, however, were in the minority and $75.4 \%$ reported they had not changed the structure of their course as a result of using WBLT. Instead, many had introduced the new technology by simply adding it onto existing practice, rather than thinking through the implications at a whole of curriculum level. Why is there reluctance to change? Apart from the obvious workload issues, the slow response may be due to what Fullan (2001) describes as a lack of belief about the need to change.

From the staff perspective there has been no strong evidence to question the role of lectures. In the survey, staff were asked about the role of lectures and whether the use of WBLT changed (enhanced or reduced) their ability to perform this role. At least $80 \%$ of respondents reported they used lectures to: inspire and motivate students; build conceptual frameworks; use multimedia content; provide structured experiences for students; impart information and make announcements; make use of audiovisual aids; and establish connections with students. As for the use of WBLT - one-third of respondents indicated that their use had resulted in no change to all but the last two items. A similar percentage felt WBLT had enhanced their ability to inspire and motivate, build conceptual frameworks, impart information, make announcements, and provide a structured experience for students. There were only two items where WBLT was perceived to diminish capability - establishing connections with students, and gauging students' understanding.

Overall these findings suggest that lecturers' beliefs about the role of lectures and the impact of WBLT on their capability to fulfil this role had not been challenged sufficiently to warrant their reconceptualising and changing the curriculum; a potentially time-consuming and disruptive task (reported more fully in Green et al. 2008; Phillips et al. 2007).

In addition, we found that many students continue to come to face-to face lectures. For those students who attended regularly $(n=519)$, they did so for a variety of reasons; namely, the visual aids were useful (49\%), live lectures were motivating $(46.5 \%)$, to have informal conversations with other students about the content $(46.6 \%)$, the presence of the lecturer added value (45.7\%), and they liked an established routine (44.2\%). For many students, using WBLT was not an either/or decision 
and they often attended lectures as well as using the technologies to complement their learning. Nevertheless, as noted earlier, a sizable number of students felt they could learn just as well from the technology. This then begs the question that if lectures are delivered with little to no audience participation, then why not replace them with WBLT and use the face-to-face time in more interactive, student-focused ways?

\section{Issues for consideration in a changing environment}

Scott notes that:

Right from the outset the driving force of change is people - their motives, histories, learned ways of behaving, perceptions and relationships. $(1999,18)$

In this study, the driving force behind the rapid uptake of WBLT has been students and their changing circumstances. WBLT have led to substantial change for students, opening up new opportunities and transforming the way they learn. Less transformational has been the impact of WBLT on the culture of university teaching. Lecturers have modified their lectures and the lecturing process to some degree; however, few have engaged in more comprehensive curriculum change.

Overall, there was not a strong sense from students or staff that the lecture is a thing of the past, and examples drawn from the vignettes and case studies revealed that WBLT can be effective tools when their use matches their purpose. Contexts where WBLT were seen to be advantageous were when a traditional lecture was delivered to large classes, when students required flexibility or when there were high proportions of non-English-speaking students. Less appropriate were contexts where the student's presence was essential for group work, discussions or presentations, where a large amount of multimedia or copyright material was being used, or where the content was sensitive or complex and required close monitoring of the reactions of students (reported more fully in Gosper et al. 2008).

Looking more broadly at the whole of institution environment, WBLT have brought a number of issues to the fore in a pragmatic way.

\section{Blurring of boundaries between internal and external students}

Where once lecture attendance differentiated external and internal enrolment modes, this is now changing. Many programmes are being offered with the same lectures being delivered to internal and external cohorts. This suggests a need to question whether the distinction between external and internal modes of enrolment is of relevance to an increasing number of students. Are these distinctions of practical relevance when it comes to learning and teaching, or are they an administrative legacy of a fading era?

\section{Introducing a new technology affects the design of the whole curriculum}

The introduction of any new technology is not an isolated experience and is likely to bring changes to other aspects of the learning and teaching environment, particularly in the ways in which students and staff communicate and in the relationship between other elements of the curriculum. Rather than focusing on the lecture alone, a shift to a whole of curriculum approach is needed. Ellis and Goodyear (2009) warn against 
using e-learning as a way of delivering information by bolting it on to course design in an unreflective way. They maintain that those with a richer understanding of learning technologies take a more holistic approach and integrate the technologies into teaching as well as the physical and virtual spaces (Ellis and Goodyear 2009).

\section{Change needs to be supported by evidence}

The introduction of WBLT has led to unforeseen implications particularly in relation to lecture attendance, which raises the question of how well staff really understand their students; their circumstances, needs and expectations. We found that staff are unsure, or not convinced that the changes taking place due to the introduction of WBLT warranted a rethinking of the role of lectures within the curriculum, even in the face of declining attendance. Hanson maintains that:

Resisting e-learning is in fact an entirely rational act designed to strengthen a relationship based on 'being there' with the students, despite the diminishing quality of that relationship due to the pressure of increased student numbers and changing student expectations. $(2009,11)$

The importance of 'being there' was clearly evident in our study, which showed that many lecturers have held onto the belief that students learn better from face-toface lectures even though this belief is clearly not held by students. Developing a strong evidence base to support change is one way to challenge these long-held beliefs. Indeed, isolation of academics from the educational research literature and evidence of good practice leading to successful outcomes are amongst the factors that are a barrier to sustainable change (Nicol and Draper 2009).

\section{Responding to change has policy and planning implications}

An observation about effecting educational change made by Fullan is that:

Successful change projects always include elements of both pressure and support. Pressure without support leads to resistance and alienation; support without pressure leads to drift or waste of resources. $(2001,92)$

Achieving the balance between pressure and support is a challenge for institutions. The findings from the staff survey indicated lecturers who reported having little sense of choice regarding the implementation of WBLT, due to pressures from the institution or their students, were more likely to hold negative attitudes. The notion of the 'self-fulfilling prophecy' emerged with some of the respondents; where if they had implemented WBLT as a result of feelings of pressure, they were more likely to report negative effects on their teaching. Under these circumstances, staff were also more conscious of their moral rights and were concerned that their privacy could be invaded by the university. An even more undesirable consequence of excessive pressure could be that WBLT are put to use in contexts where it is inappropriate or ineffective for student learning. Nevertheless, institutional commitment as displayed through policy and planning strategies and the presence of longrange and worthwhile educational aspirations with which to align the innovation to are important for ensuring the transformational change (Nicol and Draper 2009; Scott 1999). 


\section{Professional development and support is often overlooked and needs attention}

The study has highlighted several professional and organisational implications surrounding the introduction of new technologies. The relationship between choice in the use of WBLT and a positive experience with WBLT presents a strong case for empowering academics to make informed decisions about the appropriateness of technologies in their own context. Professional development programmes are an essential ongoing requirement to enable staff to develop new pedagogical models that balance the needs and expectations of students with the culture and requirements of the discipline. Programmes need to go beyond the provision of technical information and training to encompass the development of a deeper understanding of the capability of learning technologies based on sound teaching and learning principles.

\section{Conclusion}

The aim of this research was to gain a better understanding of the implications of webbased lecture technologies for learning and teaching. The study focused on the perspectives of the users of the technology. Those not making use of the technologies were outside the remit of the study.

The findings have established a rich picture of the experiences of students and staff. Students have responded positively, and for many their use has transformed learning - providing choice, flexibility and enabling them to revisit key concepts and ideas in their own time. Less transformational has been the impact on teaching, with challenges being posed through falling attendance and the perception by some of a diminished learning experience for students. There is a clear mis-match between the student experience and the way they engage in learning and the corresponding conceptions held by staff. This is bringing into question the nature of teaching and in particular the role of lectures.

Learning technologies in general, not just WBLT, will continue to act as a stimulus for change - particularly if, as we have seen in this research, they tap into the needs of students and support their learning. The ways in which students learn and communicate will continue to evolve in response to their changing environment. This highlights the importance of ongoing research to understand the nature of these changes and the implications they have for students and their learning and academics and their teaching.

\section{Acknowledgements}

Support for this publication has been provided by the Australian Learning and Teaching Council, an initiative of the Australian Government Department of Education, Science and Training. The views expressed in this publication do not necessarily reflect the views of the Council.

\section{References}

Anderson, M.J. 2006. Degree of fit: University students in paid employment, service delivery and technology. Australasian Journal of Educational Technology 22, no. 1: 88-103. http://www.ascilite.org.au/ajet/ajet122/res/anderson.html.

Australian Vice-Chancellor's Committee. 2007. Australian university student finances 2006. http://www.cshe.unimelb.edu.au/pdfs/StudentFinances2006.pdf.

Buxton, K., K. Jackson, M. deZwart, L. Webster, and D. Lindsay. 2006. Recorded lectures: Looking to the future. Paper presented at the 23rd annual ascilite conference Who's learning? 
Whose technology?, December 3-6, in Sydney, Australia. http://www.ascilite.org.au/ conferences/sydney06/proceeding/pdf_papers/p118.pdf.

Carter, H., G. Hodgson, and W.R. Sher. 2005. Developing and using interactive learning objects in a construction management course. Paper presented at the ED-MEDIA 2005 World Conference on Educational Multimedia, Hypermedia and Telecommunications, June 27-July 2, in Montreal, Canada.

Creswell, R. 2003. Research design: Qualitative, quantitative and mixed methods approaches. Thousand Oaks, CA: SAGE.

Donnan, P., M. Kiley, and C. McCormack. 2004. Lecture streaming: Getting the pedagogy right. Paper presented at the OLT, November 3, in Queensland, Australia.

Ellis, R., and P. Goodyear. 2009. Students' experiences of E-learning in higher education: The ecology of sustainable innovation. London: Taylor and Francis.

Fardon, M. 2003. Internet streaming of lecture: A matter of style. Paper presented at Educause in Australasia, May 6-9, in Adelaide Australia.

Fullan, M. 2001. The new meaning of educational change. 3rd ed. London: Routledge Falmer and Teachers College Press.

Gosper, M., D. Green, M. McNeill, R.A. Phillips, G. Preston, and K. Woo. 2008. Final report: The impact of web-based lecture technologies on current and future practices in learning and teaching. Sydney: Australian Learning and Teaching Council. http:// www.altc.edu.au/carrick/webdav/site/carricksite/users/siteadmin/public/grants_project_ webbasedlecture_report_aug08.pdf.

Green, D., M. McNeill, M. Gosper, K. Woo, R. Phillips, and G. Preston. 2008. Web based lecture technologies: A lens intensifying the changing roles of learners and lecturers. Paper presented at the Ed-Media, in Vienna, Austria.

Hanson, J. 2009. Displaced but not replaced: The impact of e-learning on academic identities in higher education. Teaching in Higher Education 14, no. 5: 553-64.

Hodgson, V. 2005. Lectures and the experience or relevance. In Experience of learning: Implications for teaching and studying in higher education, ed. F. Marton, D. Hounsell, and N. Entwistle, vol. 3, 159-71. Edinburgh: University of Edinburgh, Centre for Teaching, Learning and Assessment. http://www.tla.ed.ac.uk/resources/EoL.html.

Lefoe, G., and J. Hedberg. 2006. Blending on and off campus: A tale of two cities. In Handbook of blended learning environments: Global perspectives, local designs, ed. C. Bonk and C. Graham, 325-37. San Francisco: Pfeiffer.

Maag, M. 2006. iPod, uPod? An emerging mobile learning tool in nursing education and students' satisfaction. Paper presented at the Australasian Society for Computers in Learning in Tertiary Education (ASCILITE), December 3-6, in Sydney, Australia.

Massingham, P., and T. Herrington. 2006. Does attendance matter? An examination of student attitudes, participation, performance and attendance? Journal of University Teaching and Learning Practice 3. http://www.dest.gov.au/highered/eippubs/eip02_06/eip02_06.pdf.

McElroy, J., and Y. Blount. 2006. You, me and iLecture. In Proceedings of the 23rd annual conference of the Australasian Society for Computers in Learning in Tertiary Education: Who's learning? Whose technology?, ed. L. Markauskaite, P. Goodyear, and P. Reimann, 549-558. Sydney: Sydney University Press.

Nicol, D.J., and S.W. Draper. 2009. A blueprint for transformational organisational change in higher education: REAP as a case study. In Transforming higher education through technology enhanced learning, ed. T. Mayes, D. Morrison, H. Mellar, P. Bullen, and M. Oliver. York, UK: Higher Education Academy.

Phillips, R. 2005. Challenging the primacy of lectures: The dissonance between theory and practice in university teaching. Journal of University Teaching and Learning Practice 2, no. 1. http://jutlp.uow.edu.au/2005_v2002_i2001/phillips2003.html.

Phillips, R., M. McNeill, M. Gosper, K. Woo, G. Preston, and D. Green. 2007. Staff and student perspectives on web-based lecture technologies: Insights into the great divide. Paper presented at the ASCILITE, December 2-5, in Singapore.

Pratt, D.D., and J.B. Collins. 2001. Teaching perspectives inventory. http://teachingperspectives.com

Scott, G. 1999. Change matters: Making a difference in education and training. St Leonards, NSW: Allen \& Unwin.

Sharpe, R., G. Benfield, G. Roberts, and R. Francis. 2006. The undergraduate experience of blended e-learning: A review of UK literature and practice. The Higher Education 
Academy. http://www.heacademy.ac.uk/assets/York/documents/ourwork/research/literature_reviews/blended_elearning_full_review.pdf.

Soong, S.K.A., L.K. Chan, C. Cheers, and C. Hu. 2006. Impact of video recorded lectures among students. In Proceedings of the 23rd annual conference of the Australasian Society for Computers in Learning in Tertiary Education: Who's learning? Whose technology?, ed. L. Markauskaite, P. Goodyear, and P. Reimann, 789-93. Sydney: Sydney University Press.

Williams, J., and M. Fardon. 2007. Recording lectures and the impact on student attendance. Paper presented at the ALT-C, September 4-6, in Nottingham, UK.

Woo, K., M. Gosper, M. McNeill, G. Preston, D. Green, and R. Phillips. 2008. Web-based lecture technologies: Blurring the boundaries between face-to-face and distance learning. ALT-J 16, no. 2: 81-93. 